\title{
Family physicians understanding about Mantoux test: A survey from a high endemic TB country
}

\author{
Niloufer Sultan Ali1 ${ }^{1}$ Kishwar Jamal ${ }^{1}$ and Ali Khan Khuwaja*2
}

\begin{abstract}
Background: Tuberculosis is a global health emergency and is a big challenge to diagnose and manage it. Family physicians being first contact health persons should be well competent to diagnose and manage the patients with tuberculosis.

Aims: This study was aimed to assess the level of understanding about Mantoux Test amongst Family Physicians in Karachi, Pakistan and to determine the difference of level of understanding by gender and number of tuberculosis patients seen in a month.

Methods: A cross sectional survey was conducted among 200 Family Physicians working in Karachi; the largest city and economic hub of Pakistan. Family Physicians who attended Continuous Medical Education sessions were approached after taking consent. Pre-tested, self administered questionnaire was filled consisting of: basic demographic characteristics, questions regarding knowledge about Mantoux Test, its application and interpretation. Data of 159 questionnaires was analyzed for percentages, as rest were incomplete. Chi square test was used to calculate the difference of understanding levels between various groups.

Results: Almost two thirds of respondents were males and above 35 years of age. Majority of Family Physicians were private practitioners and seeing more than five tuberculosis patients per month. Overall, a big gap was identified about the knowledge of Mantoux Test among study participants. Only $18.8 \%$ of Family Physicians secured Excellent ( $\geq 80 \%$ correct responses). This poor level of understanding was almost equally distributed in all comparative groups (Male = $20.8 \%$ versus Female $=15.9 \% ; p-0.69$ ) and (Seen $<5$ tuberculosis patients per month $=18.6 \%$ versus seen $\geq 5$ tuberculosis patients per month $=19.3 \% ; p-0.32$ ). A huge majority of Family Physicians (92\%) however, showed keen interest in obtaining further knowledge regarding Mantoux Test and amongst them $72 \%$ suggested Continued Medical Education sessions as preferable mode of updating themselves.

Conclusion: Our study revealed an overall major deficit in understanding and interpretation of Mantoux Test amongst Family Physicians which needs to be addressed. Continues Medical Education sessions for Family Physicians should be organized in regular basis for upgrading their knowledge in this regards.
\end{abstract}

\section{Background}

Tuberculosis (TB) was declared a global health emergency by World Health Organization (WHO) [1]. According to WHO Global TB Report, Pakistan suffers from the eighth-highest burden in the world, with a TB prevalence of 263/100,000 population and TB deaths estimated at $34 / 100,000$ population [2]. In a survey, conducted in Karachi, Pakistan, Marsh et al has reported TB as a second leading cause of adult death [3]. The setbacks

\footnotetext{
*Correspondence: ali.khuwaja@aku.edu

2 Family Medicine/Community Health Sciences, Aga Khan University, Karachi, Pakistan

Full list of author information is available at the end of the article
}

and hurdles which are encountered in tackling this disease mainly include late and improper diagnosis and management [4]. Like many countries in the developing world the public health care system in Pakistan is neither very efficient nor very accessible. However, there is a very strong private health sector, particularly in the cities and a major bulk of the population consults these private family physicians (FP's). According to an estimate $80 \%$ of TB patients in urban Pakistan initially report to private FP's for their diagnosis and treatment [5]. However research focusing on TB management by the FP's is almost nonexistent. The few studies that have been conducted in 
Pakistan revealed that the knowledge and practices regarding diagnosis and management of TB is very unsatisfactory amongst FPs [6,7] which can leads to drug resistance and increased mortality [8].

Clinical research on the MT has shown that a diagnosis of active case of tuberculosis is never made solely on the results of this test [9]. Ali et al [10] has reported that $44 \%$ of healthy health care workers had a positive MT; out of them none developed active disease even after one year of follow up. Thus, tuberculin response in TB-endemic area can not be used as a diagnostic marker for active TB [11]. Hence; starting treatment just on the basis of positive MT test is never recommended.

Family physicians being first contact health persons should be well competent and updated to diagnose and manage the tuberculosis particularly in countries where tuberculosis is one of the major health problems. Several studies that have been conducted in Pakistan assessed the knowledge regarding TB and its management, but none of them have particularly focused on the knowledge and the interpretation of MT by the FPs. We therefore conducted this study to assess the in-depth knowledge, interpretation and application of the MT test amongst FPs in Karachi. Results of this study will help and guide to formulate and implement the interventions for FPs in this regards.

\section{Methods}

A questionnaire-based study was conducted among FPs who attended Continuous Medical Education sessions; which were arranged specifically for FPs in Karachi, Pakistan. After taking consent to participate in the study, a self-administered questionnaire was distributed to all (200) FP's. Full confidentiality of the information gathered was ensured to all the study participants and also assured that the results of this study would not be presented on individual level. Even though, no harm was expected to occur to any of the study participant, study questionnaire and proposal was reviewed and approved by the Research Committee of the department of Family Medicine, Aga Khan University, Karachi.

Questionnaire, consisting of basic demographic characteristics about the participants and questions regarding their knowledge about MT and its application and interpretation were filled by the respondents. Face and content validity of the questionnaire was obtained through a review process with experts in the filed. After incorporating the identified inconsistencies and inaccuracies, the questionnaire was pre-tested on a group of family medicine residents (trainees) to identify any problem relating to question design, flow and interpretation. Feedback given were incorporated accordingly. A total of 10 questions were asked from the study participants and about 20 minutes were needed to respond the questionnaire completely. Each correct response was marked as one point, those who responded five to seven questions correctly were labeled as 'Good' while those who responded correctly to eight and more questions were labeled as 'Excellent'.

Data of 159 questionnaires was analyzed using the statistical software package SPSS Version 16, remaining were not included because of incompleteness of the forms. Percentages and their $95 \%$ CIs were calculated for each variable. Chi square test was used to measure the significant difference between various groups (Male vs. female and $<5$ TB pts vs. $\geq 5 \mathrm{~TB}$ pts seen by FP per month), keeping the level of significance $(\alpha)$ at 0.05 . Out of total 159 respondents $60 \%$ were males and $73.5 \%$ were seen more than five TB patients per month.

\section{Results}

Level of knowledge about MT amongst FPs and their knowledge differences by sex and number of TB patients seen per month are summarized in Table 1 . About $30 \%$ of FP's reported the use of MT as a diagnostic tool for detection of active case of TB. More than half of the respondents did not know the correct response regarding the cutoffs for positivity of MT for both HIV and Non-HIV patients. More than two thirds of the respondents also did not know the correct possible causes of a negative MT result. Similarly, majority of responses were not correct for other questions. Overall, less than one-fifth of the study participants achieved the score of $\geq 80$ and this poor knowledge was equally prevalent in all compared groups $($ Male $=20.8 \%$, Female $=15.9 \% ; \mathrm{p}-0.69)$ and (Seen $<5$ TB patients per month $=18.6 \%$, seen $\geq 5 \mathrm{~TB}$ patients per month $=19.3 \%$; -0.32 ).

Regarding the interest to seek further knowledge about the subject, almost $92 \%$ of the respondents shown their keen interest. Amongst them, $72 \%$ had preference for continuing medical education sessions (CME) for updating themselves while the second most preferred option reported as scientific medical journals and newsletters. (Figure 1).

\section{Discussion}

To the best of our knowledge this study is so far the first of its kind conducted in high endemic country, Pakistan which specifically focused on the knowledge of MT among private FPs who are supposed to be the first contact health care providers for the community in general. This study revealed that there is an overall major deficit in the understanding and interpretation of the MT amongst FP's of either sex and irrespective of the number of TB patients they see per month.

In this study, over one-fourth of the respondents did not know the correct route of administration of MT and about one-third of FPs has reported that they use MT as a 
Table 1: Level of understanding about MT amongst FP's and their differences by gender and number of TB patients seen in a month

\begin{tabular}{|c|c|c|c|c|c|c|c|}
\hline \multirow[t]{2}{*}{ Questions } & \multirow[t]{2}{*}{$\begin{array}{l}\text { FPs responded } \\
\text { correctly (\%) }\end{array}$} & \multicolumn{2}{|c|}{ Gender (\%) } & \multirow[t]{2}{*}{ p-value } & \multicolumn{2}{|c|}{$\begin{array}{l}\text { Number of TB patients } \\
\text { seen in a month (\%) }\end{array}$} & \multirow[t]{2}{*}{ p-value } \\
\hline & & Male & Female & & $<5$ & $\geq 5$ & \\
\hline $\begin{array}{l}\text { Should MT be used as a diagnostic test to } \\
\text { detect active TB? }\end{array}$ & 66.6 & 64.6 & 68.3 & 0.38 & 64.9 & 68.3 & 0.56 \\
\hline $\begin{array}{l}\text { What is the route of administration of } \\
\text { M.T.? }\end{array}$ & 73.0 & 67.7 & 78.3 & 0.05 & 75.3 & 70.7 & 0.17 \\
\hline $\begin{array}{l}\text { How many tuberculin units should be } \\
\text { injected? }\end{array}$ & 29.6 & 33.3 & 25.9 & 0.13 & 29.9 & 29.3 & 0.57 \\
\hline $\begin{array}{l}\text { After how many hours tuberculin } \\
\text { reaction should be read? }\end{array}$ & 62.9 & 66.7 & 59.1 & 0.15 & 59.8 & 66.0 & 0.19 \\
\hline $\begin{array}{l}\text { How tuberculin reaction should be } \\
\text { measured? }\end{array}$ & 61.7 & 67.7 & 55.7 & 0.08 & 55.7 & 67.7 & 0.02 \\
\hline $\begin{array}{l}\text { What is the cutoff for positivity of MT in } \\
\text { non HIV patients? }\end{array}$ & 41.5 & 44.8 & 38.2 & 0.19 & 34 & 49.0 & 0.02 \\
\hline $\begin{array}{l}\text { What is the cutoff for positivity of MT in } \\
\text { HIV patients? }\end{array}$ & 31.4 & 31.1 & 31.7 & 0.54 & 28.9 & 33.9 & 0.20 \\
\hline $\begin{array}{l}\text { How will you manage an asymptomatic } \\
\text { patient with } \mathrm{MT} \geq 15 \mathrm{~mm} \text { ? }\end{array}$ & 50.9 & 57.3 & 44.5 & 0.04 & 46.4 & 55.4 & 0.08 \\
\hline Does negative MT exclude TB? & 89.3 & 85.4 & 93.2 & 0.04 & 89.7 & 88.9 & 0.45 \\
\hline What are the causes of negative M.T.? & 30.2 & 33.3 & 27.1 & 0.19 & 30.9 & 29.5 & 0.26 \\
\hline \multicolumn{8}{|c|}{ Overall score } \\
\hline Good & 57.9 & 60.4 & 55.4 & 0.26 & 51.5 & 64.3 & 0.07 \\
\hline
\end{tabular}

screening tool to detect active TB. Nearly three-fourths of FPs did not know the number of tuberculin units that are injected during MT and around $60 \%$ of FP's did not know that a MT reading $>10 \mathrm{~mm}$ is taken as positive in non-HIV patients in Pakistan. About half of the respondents said they would start anti-tuberculosis treatment on an asymptomatic patient with MT readings of $15 \mathrm{~mm}$ or more. About three-fourths of the respondents gave incorrect answers for the causes of negative MT and this poor understanding was equally prevalent in all comparative groups. Overall, proportions of correct responses of some of the questions were reported higher by FPs who were seeing more than five patients per month however this difference is not noteworthy.

Despite the widespread use of MT by the FPs, major gaps regarding its knowledge and clinical interpretation and application were identified. Less than one fifth of the study participants scored at the level of $\geq 80 \%$ and this low figure was equally documented among all study groups. Khan [7] and Manalo [12] also reported poor knowledge about MT among first contact health persons in high endemic TB prevalent countries.

However, it was encouraging to note that aver $90 \%$ of the FP's showed interest in gaining more knowledge about MT and its interpretation and clinical application. 


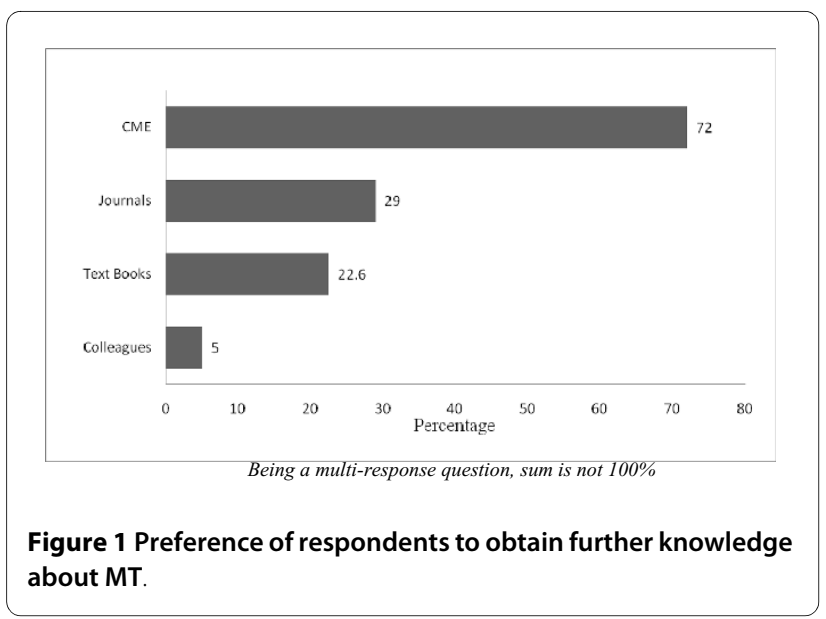

Almost two thirds expressed the need to obtain this information through CME.

\section{Conclusion}

In spite of study participants practicing in urban Pakistan and attending CMEs, a big gap was identified about the understanding of MT. We can assume even more unsatisfactory knowledge about this important topic from FPs of rural and remote settings who does not have opportunity to upgrade their medical knowledge. Continuous update on the recent evidence based knowledge should be incorporated through CME sessions, lectures, seminars, workshops and hand outs and booklets. More research work at larger scale is also suggested in this important topic amongst FPs in Pakistan.

\section{Competing interests}

The authors declare that they have no competing interests.

\section{Authors' contributions}

NSA conceived and designed the study and prepared the manuscript. KJ developed and administered the questionnaires and managed the data. AKK analyzed and interpreted the data and provided intellectual feedback throughout the study. All authors read and approved the final manuscript.

\section{Acknowledgements}

We are very much indebted to all study participants who agreed to participate in the study. We are also grateful to Mr. labal Azam, Assistant Professor - Biostatistics, Department of Community Health Sciences, Aga Khan University, for the review and comments on this manuscript.

\section{Author Details}

'Family Medicine, Aga Khan University, Karachi, Pakistan and 2Family Medicine/ Community Health Sciences, Aga Khan University, Karachi, Pakistan

Received: 18 November 2009 Accepted: 31 May 2010

Published: 31 May 2010

\section{References}

1. WHO/TB/94.177: TB a global emergency. Geneva, WHO; 1994

2. Global tuberculosis control: surveillance, planning, financing: WHO report 2008. WHO/HTM/TB/2008.393

3. Marsh DR, Kadir MM, Husein K, Luby SP, Siddiqui R, Khalid SB: Adult mortality in slums of Karachi, Pakistan. J Pak Med Assoc 2000, 50:300-306.
4. Khan JA, Malik A: Tuberculosis in Pakistan. Are we losing the battle? J PakMed Assoc 2003, 53:320-321.

5. Marsh D, Hashim R, Hassany F, et al:: Front-line management of pulmonary tuberculosis: an analysis of tuberculosis and treatment practices in urban Sindh, Pakistan. Tuber Lung Dis 1996, 77:86-92.

6. Shah SK, Sadiq H, Khalil M, Noor A, Rasheed G, Shah SM, Ahmad N: Do private doctors follow national guidelines for managing pulmonary tuberculosis in Pakistan? East Mediterr Health J 2003, 9:776-788.

7. Khan J, Malik A, Hussain H, Ali NK, Akbani F, Hussain SJ, Kazi GN, Hussain SF: Tuberculosis diagnosis and treatment practices of private physicians in Karachi, Pakistan. East Mediterr Health J 2003, 9:769-775.

8. Butt T, Ahmad RN, Kazmi SY, Rafi N: Multi-drug resistant tuberculosis in Northern Pakistan. J Pak Med Assoc 2004, 54:469-472.

9. Centre for Disease Control and Prevention: Division of Tuberculosis Elimination (DTBE). Fact Sheet [http://www.cdc.gov/TB/pubs/ tbfactsheets/skintesting eng.htm]. [Cited 2009 Mar 6]

10. Ali NS, Hussain SF, Azam SI: Is there a value of Mantoux test and erythrocyte sedimentation rate in pre-employment screening of health care workers for tuberculosis in a high prevalence country? Int J Tuberc Lung Dis 2002, 6:1012-1016.

11. Hussain R, Toossi Z, Hasan R, Jamil B, Dawood G, Ellner JJ: Immune response profile in patients with active tuberculosis in a BCG vaccinated area. Southeast Asian J Trop Med Public Health 1997, 28:764-773.

12. Manalo FMC, Pineda AV Jr, Montoya JC: Knowledge, Attitudes and Practices for Tuberculosis among Filipino Family Physicians: A Comparative Analysis by Practice Setting and Location. Phil J Microbiol Infect Dis 1998, 27:6-12.

doi: $10.1186 / 1447-056 X-9-8$

Cite this article as: Ali et al., Family physicians understanding about Mantoux test: A survey from a high endemic TB country Asia Pacific Family Medicine 2010, $9: 8$

\section{Submit your next manuscript to BioMed Central} and take full advantage of:

- Convenient online submission

- Thorough peer review

- No space constraints or color figure charges

- Immediate publication on acceptance

- Inclusion in PubMed, CAS, Scopus and Google Scholar

- Research which is freely available for redistribution
C Biomed Central 